\title{
Virtual Dissection with Clinical Radiology Cases Provides Educational Value to First Year Medical Students
}

Citation for published version (APA):

Darras, K. E., Forster, B. B., Spouge, R., de Bruin, A. B. H., Arnold, A., Nicolaou, S., Hu, J., Hatala, R., \& van Merrienboer, J. (2020). Virtual Dissection with Clinical Radiology Cases Provides Educational Value to First Year Medical Students. Academic Radiology, 27(11), 1633-1640.

https://doi.org/10.1016/j.acra.2019.09.031

Document status and date:

Published: 01/11/2020

DOI:

10.1016/j.acra.2019.09.031

Document Version:

Publisher's PDF, also known as Version of record

Document license:

Taverne

Please check the document version of this publication:

- A submitted manuscript is the version of the article upon submission and before peer-review. There can be important differences between the submitted version and the official published version of record.

People interested in the research are advised to contact the author for the final version of the publication, or visit the DOI to the publisher's website.

- The final author version and the galley proof are versions of the publication after peer review.

- The final published version features the final layout of the paper including the volume, issue and page numbers.

Link to publication

\footnotetext{
General rights rights.

- You may freely distribute the URL identifying the publication in the public portal. please follow below link for the End User Agreement:

www.umlib.nl/taverne-license

Take down policy

If you believe that this document breaches copyright please contact us at:

repository@maastrichtuniversity.nl

providing details and we will investigate your claim.
}

Copyright and moral rights for the publications made accessible in the public portal are retained by the authors and/or other copyright owners and it is a condition of accessing publications that users recognise and abide by the legal requirements associated with these

- Users may download and print one copy of any publication from the public portal for the purpose of private study or research.

- You may not further distribute the material or use it for any profit-making activity or commercial gain

If the publication is distributed under the terms of Article $25 \mathrm{fa}$ of the Dutch Copyright Act, indicated by the "Taverne" license above, 


\title{
Virtual Dissection with Clinical Radiology Cases Provides Educational Value to First Year Medical Students
}

\author{
Kathryn E. Darras, MD, FRCPC, Bruce B. Forster, MSc, MD, FRCPC, FACR, Rebecca Spouge, BSc, \\ Anique BH de Bruin, PhD, Abigail Arnold, MSc, Savvas Nicolaou, MD, FRCPC, Jeff Hu, MD, FRCPC, \\ Rose Hatala, MD, MSc, Jeroen van Merriënboer, PhD
}

\begin{abstract}
Rationale and Aim: In virtual dissection, three-dimensional computed tomography scans are viewed on a near-life size virtual dissection table and through touchscreen technology, students work together to manipulate the data to perform their dissection. The purpose of this study was to develop a Virtual Dissection Curriculum for first year medical students and to assess its educational value as well as students' preferred pedagogy for learning with this new technology.

Methods: One hundred and five first-year medical students participated in a case-based virtual dissection curriculum and were invited to complete a theory-based post experience survey. Eight unique clinical cases were selected based on the first-year curricular objectives and divided into four 30-minute sessions. In groups of 6-8, students reviewed the cases with a radiologist. First, students' reactions to virtual dissection were measured by three constructs using a 5-point Likert scale: quality of curriculum design (11 questions), impact on learning (7 questions), and comfort with technology (3 questions). Second, students ranked the usefulness of six pedagogical approaches for this technology. Responses were tabulated and rank order item lists were generated statistically using the Schulze method where appropriate.
\end{abstract}

Results: The survey response rate was $83 \%$ (87/105). Overall, students' reactions to virtual dissection were positive across all three measured constructs. Most students indicated that the cases were of an appropriate level of difficulty (90\%) and that virtual dissection improved their understanding of disease and pathology (89\%), the clinical relevance of anatomy (77\%), and visuospatial relationships (64\%). Almost all students $(94 \%)$ reported that the curriculum improved understanding of the role of the radiologist in patient care. Students felt that the "very useful" pedagogical approaches were small group demonstration (68\%) and problem-based learning (51\%).

Conclusion: First-year medical students perceive the use of virtual dissection as a valuable tool for learning anatomy and radiology. This technology enables the integration of clinical cases and radiology content into preclinical learning.

(C) 2019 The Association of University Radiologists. Published by Elsevier Inc. All rights reserved.

\section{INTRODUCTION}

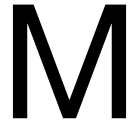

edical anatomy curricula are rapidly changing due to the emphasis on early clinical exposure, reduced curricular time, and availability of new technology $(1,2)$. Educational technologies are being used in

\section{Acad Radiol 2020; 27:1633-1640}

From the Department of Radiology, University of British Columbia, 3350-950 W 10th Avenue, Vancouver, BC Canada V5Z 1 M9 (K.E.D., B.B.F.t.F.s.h.t.a.d.., R.S t.S.s.h.d.a.B., A.A., S.N., J.H.); School of Health Professions Education, Maastricht University, Maastricht, the Netherlands (K.E.D., A.B.d.B.t.b.A.B.d.B., J.v.M.); Department of Medicine, Faculty of Medicine, University of British Columbia, Vancouver, BC, Canada (R.H.). Received May 7, 2019; revised September 15, 2019; accepted September 17, 2019. Address correspondence to: K.E.D e-mails: rostonke@gmail.com, darraske@gmail.com

(c) 2019 The Association of University Radiologists. Published by Elsevier Inc. All rights reserved.

https://doi.org/10.1016/j.acra.2019.09.031 the classroom to make the most efficient use of curricular time. This coincides with increasing emphasis on medical student radiology education with societies, like the Association of University Radiologists, publishing suggested competencies for graduating medical students $(3,4)$. Most often, radiology is integrated into anatomy instruction with increasing literature on integrating it into anatomy teaching prior to clerkship (ie, preclinical) $(5,6)$.

The shifting landscape of medical anatomy education provides the opportunity to use educational technologies to increase students' exposure to radiology in preclinical anatomy (7). The main methods on integrating radiology into anatomy instruction have been single or stacked two-dimensional (2D) radiology images and ultrasound (6). However, with advances in technologyenabled learning, three-dimensional (3D) visualization systems, such as virtual dissection tables (VDTs), can be used to teach 
radiological anatomy through virtual dissection (8). In virtual dissection, patient computed tomography (CT) scans (either normal or diseased) are loaded onto the near life-size VDTs and through powerful software interactions learners can work together to manipulate the data to virtually perform their dissection. The VDT interface is modeled after picture archiving communication system (PACS) software except that it is touchscreen rather than mouse-driven, allowing for more immersive interaction (9).

Virtual dissection presents an opportunity for radiologists to become more involved in medical student teaching and to provide students with a positive image of the speciality early in their training. Branstetter et al demonstrated that preclinical radiology teaching leads to students having more interest in radiology, higher opinions of the specialty, improved research interests, enhanced knowledge, improved understanding for ordering appropriate imaging, and decreased misconceptions about radiologists $(10,11)$. Radiologists are modern-day anatomists and virtual dissection presents an opportunity for radiologists to leverage new technology to add value to anatomy education (12).

The purpose of this study was two-fold. Our first aim was to develop a case-based Virtual Dissection Curriculum for first-year medical students to strengthen their understanding of clinical anatomy concepts using established instructional design methods and to explore the current and potential role for virtual dissection in anatomy education. The curriculum was developed and evaluated using the CIPP (context/input/ process/product) model, which is grounded in systems theory and includes four phases: context (determining program needs and goals), input (defining resources/supports available for program development), process (program monitoring), and product (measuring outcomes). $(13,14)$. This study represents the "process" phase in the CIPP model and we developed three constructs to measure students' reactions to the virtual dissection curriculum: quality of curriculum design, impact on learning, and comfort with technology. Our second aim was to determine students' preferred pedagogical approaches for learning with this new technology.

\section{METHODS}

\section{Participants}

All students in the first-year of medical school at a single institution could participate in this study $(n=292)$. The Virtual Dissection Curriculum was offered as voluntary, extracurricular sessions distributed over the first semester of medical school. In total, 36.6\% (105/292) of all first-year students participated in this new curriculum. Institutional review board approval was obtained.

\section{Materials}

Curriculum Development

The CIPP model of program evaluation plays a role in curriculum development by identifying the problems that the new intervention will address through Context studies. Through a needs assessment survey, we identified that medical students are less comfortable with radiological anatomy concepts than cadaveric anatomy concepts despite being primarily responsible for understanding image interpretation during their careers (15). An interdisciplinary committee, including medical students, radiology residents, anatomists, educational experts, and practicing physicians, was established to develop a case-based Virtual Dissection Curriculum which complimented the content presented in the medical school curriculum.

Curriculum mapping was performed to identify the objectives relevant to radiology and anatomy (16). These were reviewed by the committee and the objectives deemed suitable for virtual dissection were crossreferenced against established undergraduate radiology objectives (4). A final set of virtual dissection objectives were developed according to Bloom's Taxonomy and were divided into four laboratories (spine, chest, abdomen, and pelvis) with two cases per laboratory to form the Virtual Dissection Curriculum (Table 1) (17). Clinical cases (seven CT scans and one MRI scan) were then selected from the VDT database based on the learning objectives by the curriculum developers who have over 35 years of medical student teaching experience collectively (9). The case-based format was chosen to strengthen the vertical integration of the anatomy curriculum and also because the literature suggests that students prefer to learn anatomy through clinical vignettes (18-20). This is inline with other aspects of the first-year curriculum, where early participation in patient encounters and clinical decision-making sessions is emphasized to strength students' applied basic sciences knowledge. The curriculum committee ensured that each case only demonstrated a single disease state so that cases were not too complex for first-year students.

During the four 30-minute virtual dissection laboratories, groups of 6-8 students performed the virtual dissection tasks with a tutor, who was a radiologist with 5 years of teaching experience. One tutor taught all four sessions to provide all groups with the same experience. The laboratories were taught using a hybrid approach between small group demonstration and problem-based learning $(21,22)$. Students were taught the basic virtual dissection techniques by the instructor at the beginning of each session. Each session began with the $2 \mathrm{D}$ grayscale CT images and then transitioned to the $3 \mathrm{D}$ reconstructed images to help students understand the relationship betweeh the 2D and 3D CT images.

During the session, students were asked leading questions about their approach to the case and observations of the disease process based off the objectives (Table 1). For example, in Case 1 (scoliosis), students were asked "What observations can you make about the relative differences in the hemi-thoraces?" in order to encourage them to think anatomically to deduce the patient's symptoms. In addition, students were asked more open-ended questions to encourage integration with other aspects of the curriculum. For example, in Case 5 (abdominal aortic aneurysm), students were asked "Can you recall a patient with this disease?" and one student was able to explain to the group the disease risk based on a patient history 
TABLE 1. Virtual Dissection Curriculum. The Selected Clinical Cases (7 CT Scans and 1 MRI) Followed the Four Major Themes in the First-Year Medical Curriculum: Spine, Chest, Abdomen, and Pelvis. During Each 30-Minute Session, Two Clinical Cases Were Covered

\begin{tabular}{ll} 
Topic & Virtual Dissection Cases \\
\hline Spine & Case 1: Scoliosis, CT scan
\end{tabular}

Virtual Dissection Objectives

Spine

Case 2: Facial/cervical spine fractures, CT scan

Chest Case 3: Pneumothorax, CT scan

Case 4: Cardiac transplant, CT scan

\begin{abstract}
Abdomen Case 5: Abdominal aortic aneurysm (pre- and post-treatment), CT scan
\end{abstract}

Case 6: Renal transplant, CT scan

\begin{abstract}
Pelvis Case 7: Normal pregnancy (second trimester), MRI scan
\end{abstract}

Case 8: Complex pelvic fractures, CT scan
1. Identify this patient's abnormal spinal curvature and describe how it differs from normal.

2. List the symptoms that this patient was likely to experience as a result of his scoliosis.

3. Describe the management of this patient.

1. Identify the fractures and describe the mechanism of injury.

2. Identify the support equipment for this patient and determine the function of each.

3. Describe the management of this patient.

1. Identify the abnormal lung and describe how its appearance explains the pathophysiology of a pneumothorax.

2. Identify the chest tube and describe how it is inserted.

3. Describe the clinical complications that can arise from a tension pneumothorax.

1. Identify the supporting lines and tubes and determine the function of each.

2. List diagnoses that could be managed with a cardiac transplant.

3. Describe the rationale for transplanting the heart and lungs vs. the heart only.

1. Identify the aortic aneurysm and explain the criteria for diagnosis.

2. Describe the risk factors that this patient has for developing an aortic aneurysm.

3. Describe the management of this patient.

1. Identify the transplanted kidney and explain the rationale for its location.

2. Identify the ureterovesicular stent and explain why it is placed post-surgery.

3. List diagnoses that could be managed with a renal transplant.

1. Identify the fetus and placenta and describe their orientation with the uterus.

2. Identify the normal fetal structures and list examples of how congenital abnormalities may alter their appearance.

3. List problems that may occur in pregnancy requiring imaging.

1. Identify the supporting lines and tubes for this patient and determine the function of each.

2. Identify the patient's fractures and describe the reason why they occurred in this pattern.

3. Describe the management of this patient and the complications that may occur. session she had completed earlier in the year. Questions were developed based the recommendations for small group learning and learning through questioning $(20,21)$. Another goal of the tutor's questions was to ensure that students focused on the "big picture" and were not overwhelmed by the objectives given their limited clinical knowledge. This approach is used throughout our medical school curriculum, which is a spiral curriculum, where students revisit important concepts in an iterative process throughout the four years (23).

Students were also asked to use virtual dissection techniques to demonstrate important anatomic structures to their group. For example, in Case 2 (facial/cervical spine fractures), a student was asked "to rotate and slice the image to display the posterior extent of the frontal bone fracture." Students were encouraged to collaborate to perform these actions with one student activating the "slicing" tool while another student performed the "cut." Overall, each student had the opportunity to directly interact with the table for approximately 5 minutes per session (for a total of 20 minutes over the course of the curriculum).

\section{Survey Development}

The theory-based postexperience survey contained two main parts: students' reactions to virtual dissection and students' preferred pedagogical approaches for using this technology. The first part of the survey was based on Level 1 of the Kirkpatrick's Hierarchy for curriculum evaluation, which 
considers the educational value of curricula using four levels: (1) Reaction, (2) Learning, (3) Behavior, and (4) Results (13). Learner's reactions (ie, Kirkpatrick Level 1) were assessed through three constructs: quality of curriculum design (11 questions), impact on learning (7 questions), comfort with technology (3 questions). These constructs were developed from a literature review, student input, and the expert opinion of the interdisciplinary curriculum committee. For the second part of the survey, students ranked the usefulness of six pedagogical approaches on a 5-point Likert scale that were selected by experts as relevant to radiology education, anatomy education, and the technology: small group demonstration, large group demonstration, problem-based learning, independent learning, assessment and online modules. The Virtual Dissection Curriculum primarily utilized small group demonstration. The option "problem-based learning" refers to the use of the VDTs in established problem-based learning-for example when patient imaging is viewed (22). In addition, demographic data and student's, prior exposure to anatomy/radiology was collected.

\section{Procedure}

Upon completion of the curriculum, students completed an anonymous online survey, which was sent to them by email. The survey remained open for four weeks and a reminder email was sent each week to maximize the response rate. Students' responses were tabulated and where appropriate, a rank order of these items was generated statistically using the Schulze method (24).

\section{RESULTS}

\section{Participants}

In total, 36\% (105/292) of the first-year class participated in the Virtual Dissection Curriculum. Of the 105 participants, most (73\%) attended all four sessions. Of the 28 students who attended only three sessions, $82 \%(23 / 28)$ reported that it was due to scheduling conflicts; $7 \%$ indicated they had signed up late $(2 / 28)$ and $11 \%(3 / 28)$ indicated illness or missed reminders.

The survey response rate was $83 \%(87 / 105)$ with $62 \%$ male and $39 \%$ female respondents. Prior exposure to human anatomy varied, with $43 \%$ having had taken an anatomy course; $30 \%$ having no previous exposure; $23 \%$ having had 1-2 lectures in anatomy; and 3\% having a degree that exposed them to anatomy (Fig 1). Conversely, most (82\%) participants had no exposure to radiology before medical school (Fig 1).

\section{Curriculum Design}

Among respondents, 35\% "strongly agreed" and 55\% "agreed" that the Virtual Dissection Curriculum complemented the material presented elsewhere in the curriculum. Overall, respondents indicated that the cases shown were of an appropriate level of difficulty (Table 2). This was followed by the facial/cervical spine fracture which students found memorable for students because they were able to dissect off the skull to see the fracture from inside the cranial vault and they could see the displaced fragments of bone in the cranial vault in 3D. 94\% of respondents "agreed" or "strongly agreed" that the level of guidance provided by the tutor

\section{Exposure To Human Anatomy and Radiology Prior To Medical School}

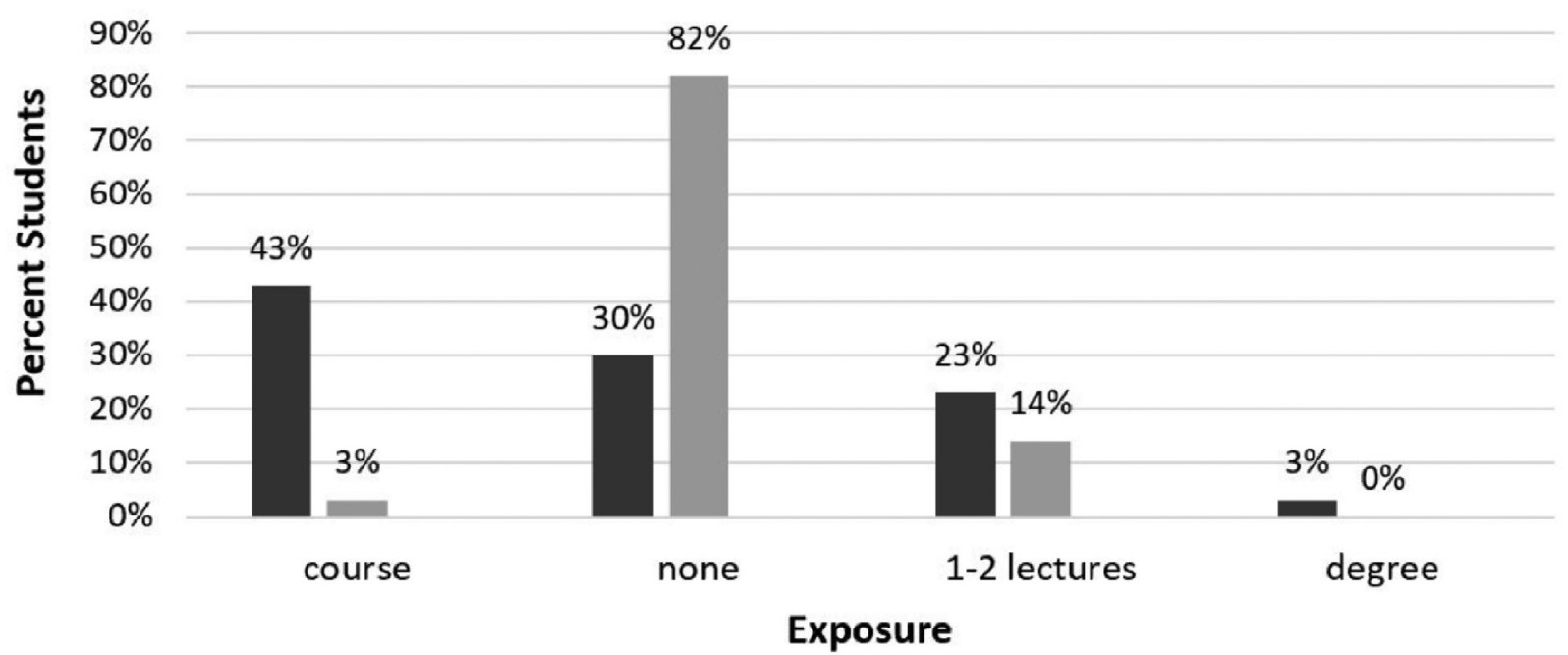

- human anatomy $\quad$ radiology

Figure 1. Participants' exposure to human anatomy and radiology prior to medical school. 
TABLE 2. Students' Perception of the Difficulty of the Virtual Dissection Curriculum. Students Were Asked to Rate the Difficulty of Each Case As Well As the Overall Curriculum on a 5Point Likert Scale (1 = Very Easy; 2=Easy; 3=Appropriate; 4 = Difficult; 5 = Very Difficult)

Students' Perceived Difficulty of the Virtual Dissection Curriculum

\begin{tabular}{llc}
\hline Curriculum & Diagnosis & Difficulty Mean (SD) \\
\hline Case 1 & Facial fracture & $2.97( \pm 0.29)$ \\
Case 2 & Scoliosis & $2.86( \pm 0.48)$ \\
Case 3 & Pneumothorax & $2.92( \pm 0.36)$ \\
Case 4 & Heart surgery & $3.07( \pm 0.30)$ \\
Case 5 & Aortic aneurysm & $2.91( \pm 0.41)$ \\
Case 6 & Renal transplant & $3.05( \pm 0.27)$ \\
Case 7 & Pregnancy & $3.00( \pm 0.31)$ \\
Case 8 & Pelvic Trauma & $3.02( \pm 0.37)$ \\
Overall & & $2.95( \pm 0.22)$ \\
\hline
\end{tabular}

Abbreviation: $\mathrm{SD}=$ Standard deviation .

improved understanding of the role of the radiologist in patient care $(4.6 \pm 0.66)$. In addition, $68 \%$ of respondents indicated it was "very important" or "important" for the virtual dissection tutor to have clinical experience.

\section{Impact on Learning}

Students were asked how virtual dissection impacted their understanding in several domains related to anatomy education (Table 3). Most respondents "strongly agreed" that virtual dissection improved their perceived understanding of the clinical relevance of anatomy (77\%), knowledge of radiological anatomy $(75.9 \%)$, and understanding of visuospatial relationships (64.4\%). When these domains were ranked from most

TABLE 3. Impact of Virtual Dissection on Students' SelfReported Understanding of Anatomy. For Each Area, Students Were Asked Their Agreement with Three Statements on a 5-Point Likert scale (1=Strongly Disagree; 2 = Disagree; $\mathbf{3}=$ Neither Agree Nor Disagree; 4 = Agree; 5 = Strongly Agree). It Should Be Noted that Students Received Ten 30-Minute Radiology and 50-Minute Cadaveric Anatomy Didactic Lectures as Part of Their Course, Which Only Included Normal Structures

Impact of Virtual Dissection on Students' Understanding of Anatomy

\begin{tabular}{lc}
\hline Domain & $\begin{array}{c}\text { Level of Understanding } \\
\text { Mean (SD) }\end{array}$ \\
\hline $\begin{array}{l}\text { Clinical relevance of anatomic } \\
\text { structures }\end{array}$ & $4.71( \pm 0.64)$ \\
Cadaveric anatomy knowledge & $4.20( \pm 0.86)$ \\
Radiology anatomy knowledge & $4.71( \pm 0.64)$ \\
Anatomy lecture content & $4.31( \pm 0.80)$ \\
Radiology lecture content & $4.60( \pm 0.67)$ \\
Visuospatial relationships & $4.59( \pm 0.65)$ \\
\hline
\end{tabular}

Abbreviation: $\mathrm{SD}=$ Standard deviation. improved to least improved by virtual dissection, respondents selected: clinical relevance, radiological anatomy, visuospatial relationships, and cadaveric anatomy. In addition, $88.5 \%$ of respondents "agreed" or "strongly agreed" that virtual dissection improved their understanding of disease and pathology $(4.5 \pm 0.83)$. The Aortic Aneurysm case was most frequently cited as being the most memorable because the imaging made it easier to understand the disease and corresponding radiological presentation. This was followed by the facial/cervical spine fracture case which students found memorable because they were able to dissect off the skull to see the fracture from inside the cranial vault and the appreciate displaced bone fragments of bone in $3 \mathrm{D}$.

\section{Comfort with Technology}

There were varying degrees of comfort in performing virtual dissection techniques, such as image cutting, zooming, and rotating the 3D CT scan images. 44\% of respondents were "comfortable" with performing basic table functions; $21 \%$ were "uncomfortable" and 7\% "very comfortable" (Fig 2).

$72 \%$ of respondents indicated that the 30-minute session duration was "appropriate" length of time to interact with the VDT while 5\% indicated that this time was insufficient. Most students (74\%) felt the ideal number of students to have around the table was $4-6$.

\section{Pedagogical Approaches}

Most respondents felt that the "very useful" approaches were small group demonstration (67.8\%) and problem-based learning $(51 \%)$ (Table 4). When the pedagogical approaches were ranked in priority order of perceived usefulness from most useful to least useful, respondents selected: small group demonstration, problem-based learning, independent learning, online content (eg modules), assessment, and large group demonstration.

\section{DISCUSSION}

Our study demonstrates how virtual dissection with clinical radiology cases can be incorporated into the first-year medical curriculum and provide students with learning opportunities that they perceive as valuable. The results of the first assessed construct (quality of curriculum design), reveal that virtual dissection laboratories are perceived as an effective method to introduce clinical radiology cases to first-year medical students. Despite the complexity of several of the included cases, students reported that the curriculum was an appropriate level of difficulty. This finding was unexpected as we anticipated that some cases (ie, complex pelvic fractures) would be challenging for a first-year medical student. Possibly, the 3D reconstructed images or the act of virtually dissecting the images enabled students to grasp the complexities of the case better than viewing standard 2D grayscale CT images. Another hypothesis is that the clinical background of the tutor (ie, radiologist) provided students with adequate 


\section{Comfort Level with Performing Virtual Dissection}

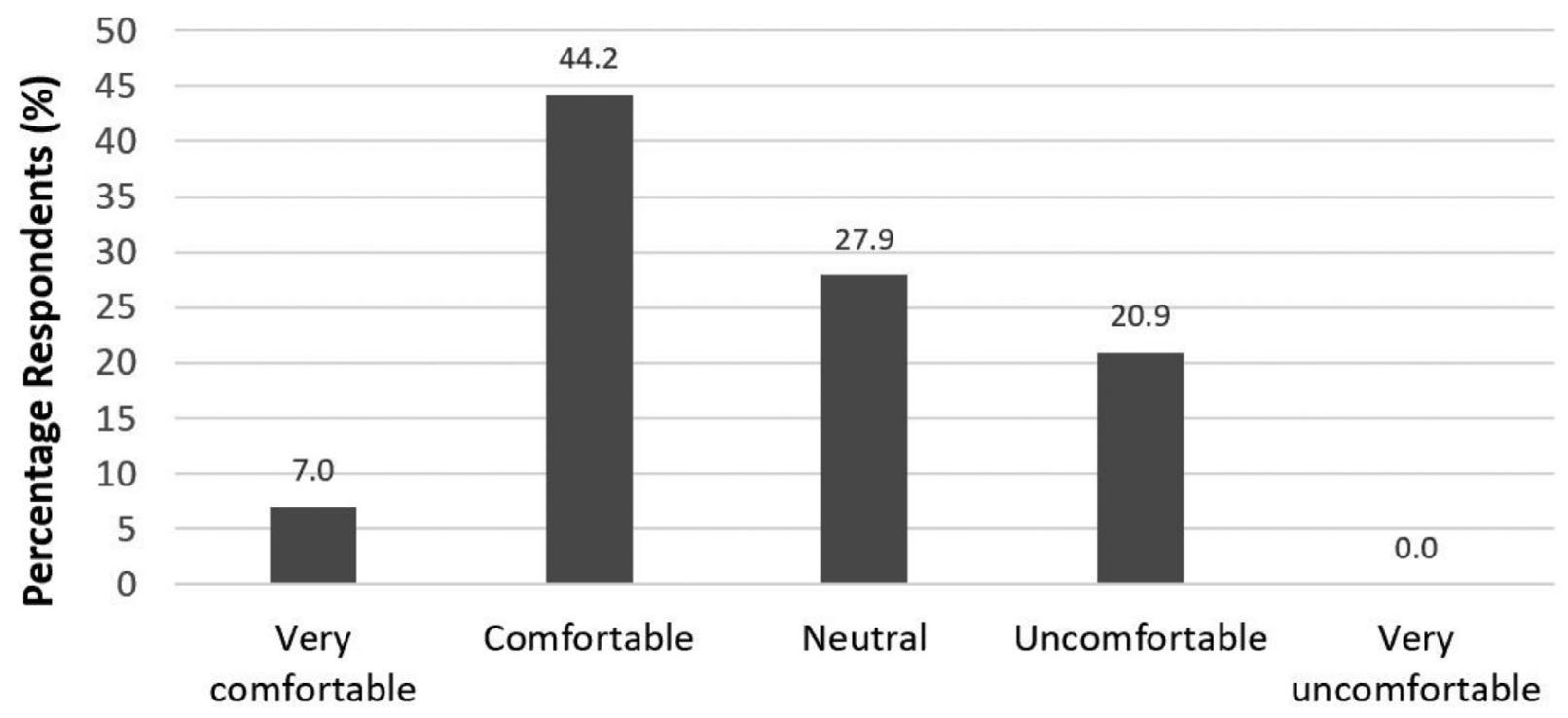

\section{Reported Comfort Level}

Figure 2. Students' self-reported comfort with performing virtual dissection. Respondents ranked their comfort on a 5-point Likert scale ( 1 = very easy; 2 = easy; 3 = appropriate; 4 = difficult; 5 = very difficult)

guidance to compensate for the complexity of the cases. Further research is required to better understand the factors which contributed to this observation.

Virtual dissection is an emerging technology used to teach anatomy using cross-sectional imaging studies; however, our study is one of the first to use this technology to teach medical students the clinical applications of anatomy through reallife clinical cases. A 2018 study by Fyfe et al reported mixed feedback from undergraduate nonprofessional Bachelor of Science students using virtual dissection for anatomy teaching $(25,26)$. In this study, students appreciated being able to view anatomic relationship in life-size, they also reported limited opportunities for group interactions and frustration with the learning curve for the technology. These findings were not echoed in our study, possibly because we used a different virtual dissection system with a more clinical interface, which may have led medical students to invest more into learning

TABLE 4. Perceived Usefulness of Various Pedagogical Approaches for Teaching with Virtual Dissection. Students Ranked Various Pedagogical on a 5-Point Likert Scale ( 1 = Not Useful; 2 = Somewhat Useful; $3=$ Neither Agree or Disagree; 4 = Useful; 5 = Very Useful)

Usefulness of Various Pedagogical Approaches

\begin{tabular}{lc}
\hline Pedagogical Approach & Usefulness Mean (SD) \\
\hline Small group demonstration & $4.72( \pm 0.48)$ \\
Problem-based learning & $4.42( \pm 0.70)$ \\
Independent learning & $4.20( \pm 1.00)$ \\
Online modules & $4.00( \pm 1.02)$ \\
Assessment & $3.52( \pm 1.17)$ \\
Large group demonstration & $3.19( \pm 1.33)$ \\
\hline
\end{tabular}

the technology, since they will need to know the basics of image interpretation during their careers. This hypothesis is supported by a 2017 study by Paech et al, which showed that examining cadaveric CT scans using the same virtual dissection system we used significantly improved the performance of medical students in general gross anatomy (27). However, this study did not focus on clinical cases or diseases. One of the advantages of using patient cases (versus cadaveric CT scans), is that students can view the "living anatomy," such as the appearance of aerated lungs or normal distension of blood vessels (ie, arteries versus veins) (8). In this way, CT scans from living patients shows students physiologic process as well as anatomic structures.

Beyond virtual dissection, several studies outside of radiology have demonstrated advantages to learning from 3D systems. In 2015, it was shown that graduate students participating in a combined augmented curriculum, which used both cadaveric dissection and 3D technology, performed better on cadaveric laboratory exams (28). Additionally, in a separate study, students reported improved understanding of spatial relationships within the human body after experiencing a combined cadaveric and 3D technology curriculum (29). Again, these studies only included normal anatomy and did not use clinical images of disease.

We found that students reported that virtual dissection improved their understanding of the role of the radiologist in patient care. This finding is supported in the literature where Branstetter et al reported that exposing students to radiology in the first year of medical school improves their impression of radiology as a specialty and increases their interest in radiology as a career (11). Seeing and interacting with CT scans through virtual dissection not only familiarizes students with the disease 
processes but also with how medical imaging works and is used in the clinical setting. The VDTs used in our study have nearly the same interface as PACS workstations and therefore show students how radiology is practiced clinically. The only exception is that the VDTs use a touchscreen interface which is not present on clinical PACS units. As a cornerstone of modern healthcare, it is essential for students to understand the role of radiology in patient diagnosis and management. One of the reasons why students responded positively virtual dissection may have been that the VDT used in our curriculum had a clinical interface which provided them with a more authentic clinical encounter.

Our findings related to the second construct (impact on learning) add to the emerging literature on the importance of vertical integration in medical education (19). Vertical integration occurs when students are taught clinical concepts at the same time as basic science concepts to make the learning encounters more authentic for future physicians (19). In our study, students reported that virtual dissection enhanced their understanding of the clinical relevance of anatomy and pathologic conditions suggesting that that virtual dissection can be used to teach anatomy in a more clinically relevant context so that students can apply what they have learned in the laboratory directly to patient encounters. This observation is corroborated by a recent study, that found that students did not value anatomy pedagogy taught outside of clinical context (30). Although the cases selected our Virtual Dissection Curriculum were from the electronic database associated with our virtual dissection system, local institutional cases can also be uploaded, allowing for maximum flexibility when designing curricula.

For our second aim, students perceived the most useful pedagogical approaches to learning with virtual dissection to be small group demonstration and problem-based learning. Students' selected pedagogical approaches are in line with current theories in medical education, where there is emphasis on collaborative learning (31). However, this finding should be interpreted with caution as these were the only two types of pedagogical approaches that students were exposed to in our Virtual Dissection Curriculum. Students felt that group learning should include no more than 4-6 learners, suggesting that students valued the time to interact with the VDT. In our curriculum, there was an average of eight students around the VDT for each small group demonstration which may have contributed to lower student comfort using the technology with only $44 \%$ reporting that they were "comfortable" and 21\% stating that they were "uncomfortable." To facilitate effective collaborative learning with the VDT, students must have enough opportunity to interact with the case and in future iterations of the curriculum, more time should be allotted "hands on" interaction. Monitoring the interaction between learners affects individual learning represents an opportunity for future research.

The primary limitation of this study is that students selfselected to participate in the Virtual Dissection Curriculum and likely have a predilection for anatomy, radiology and/or visual spatial learning. Given the limited curricular time in medical school, our extra-curricular approach was the most expeditious way to begin to evaluate this technology prior to formal integration into the curriculum. A second limitation is that this is a Process study in the CIPP model for curriculum evaluation and does not objectively assess program outcomes (ie, a change in students' knowledge/behavior). The goal of a Process study is to determine if the educational intervention is progressing as planned, which we achieved through three survey constructs developed from the literature and expert opinion. Since virtual dissection is an emerging educational technology, it is important to collect this data as a first step in understanding its role in education.

\section{CONCLUSIONS}

A case-based VDT virtual dissection curriculum using clinical CT scans is valuable to first-year medical students' learning experience, particularly in anatomy education. This technology enables the integration of clinical cases into preclinical learning and facilitates the inclusion of radiology-specific content. We recommend that radiology educators consider including virtual dissection into their preclinical undergraduate radiology curricula to strengthen the link between the basic and clinical sciences as well as to demonstrate the role of the radiologist in patient care. Students favored small group demonstration and problem-based learning as their preferred pedagogical approaches for learning with this technology.

\section{FUNDING}

This study was funded through a 2017 Radiological Society of North America Education Scholar Grant.

\section{REFERENCES}

1. Sugand K, Abrahams $P$, Khurana A. The anatomy of anatomy: a review for its modernization. Anat Sci Educ 2010; 3(2):83-93.

2. Drake RL. A retrospective and prospective look at medical education in the United States: trends shaping anatomical sciences education. J Anat 2014; 224(3, SI):256-260.

3. Pascual TNB, Chhem R, Wang SC, et al. Undergraduate radiology education in the era of dynamism in medical curriculum: an educational perspective. Eur J Radiol 2011; 78(3):319-325.

4. P. Lewis, K. Shaffer, and A. Donovan, "AMSER National Medical Student Curriculum," 2012. [Online]. Available: https://www.aur.org/SecondaryAlliances.aspx?id=141. [Accessed: 20-Feb-2018].

5. Lee JS, Aldrich JE, Eftekhari A, et al. Implementation of a new undergraduate radiology curriculum: experience at the University of British Columbia. Can Assoc Radiol J 2007; 58(5):272-278.

6. Kourdioukova EV, Valcke M, Derese A, et al. Analysis of radiology education in undergraduate medical doctors training in Europe. Eur $\mathrm{J}$ Radiol 2011; 78(3):309-318.

7. Phillips AW, Smith SG, Straus CM. The role of radiology in preclinical anatomy: a critical review of the past, present, and future. Acad Radiol 2013; 20(3):297-304. e1.

8. Darras KE, de Bruin ABH, Nicolaou S, et al. Is there a superior simulator for human anatomy education? How virtual dissection can overcome the anatomic and pedagogic limitations of cadaveric dissection. Me. Teach 2018: 1-2.

9. "Sectra anatomy visualization table." [Online]. Available: http://www.sectra.com/medical/sectra_table. [Accessed: 04-Apr-2017]. 
10. Branstetter BF, Faix LE, Humphrey AL, et al. Preclinical medical student training in radiology: the effect of early exposure. Am J Roentgenol 2007; 188(1):W9-W14.

11. Branstetter IV BF, Humphrey AL, Schumann JB. The long-term impact of preclinical education on medical students' opinions about radiology. Acad Radiol 2008; 15(10):1331-1339.

12. Darras KE, Forster BB, Nicolaou S, et al. A golden opportunity for radiologists: bringing clinical relevance to undergraduate anatomy through virtual dissection. Can AssocRadiol J 2017; 68(3):232-233. Canada.

13. Frye AW, Hemmer PA. Program evaluation models and related theories: AMEE Guide No. 67. Med Teach 2012; 34(5):e288-e299.

14. Stufflebeam DL, Shinkfield AJ. Evaluation theory, models, and applications. San Francisco: Jossey Bass/John Wiley \& Sons, Inc, 2007.

15. Darras K, Lee J, de Bruin A, Nicolaou S, et al. Cadaveric versus radiology anatomy: do we have the right balance to prepare medical students to be physicians? FASEB J 2018; 32(1_supplement):636. 3-636.3.

16. Harden RM. AMEE Guide No. 21: curriculum mapping: a tool for transparent and authentic teaching and learning. Med Teach 2001; 23(2):123-137.

17. Phillips AW, Smith SG, Straus CM. Driving deeper learning by assessment: an adaptation of the revised bloom's taxonomy for medical imaging in gross anatomy. Acad Radiol 2013; 20(6):784-789.

18. Ikah DSK, Finn GM, Swamy M, et al. Clinical vignettes improve performance in anatomy practical assessment. Anat Sci Educ. 2015; 8(3):221-229.

19. Dahle LO, Brynhildsen J, Fallsberg MB, et al. Pros and cons of vertical integration between clinical medicine and basic science within a problem-based undergraduate medical curriculum: examples and experiences from Linköping, Sweden. Med Teach 2002; 24(3):280-285.

20. Brynhildsen J, Dahle LO, Behrbohm Fallsberg M, et al. Attitudes among students and teachers on vertical integration between clinical medicine and basic science within a problem-based undergraduate medical curriculum. Med Teach 2002; 24(3):286-288

21. Allchin D. Problem- and case-based learning in science: an introduction to distinctions, values, and outcomes. CBE Life Sci Educ 2013; 12 (3):364-372.

22. Barrows HS, Tamblyn RM. Problem-based learning: an approach to medical education. Springer Publishing Company, 1980.
23. HARDEN RM. What is a spiral curriculum? Med Teach 1999; 21(2): 141-143.

24. Schulze M. A new monotonic, clone-independent, reversal symmetric, and condorcet-consistent single-winner election method. Soc Choice Welfare 2011; 36(2):267-303.

25. Fyfe G, Fyfe S, Dye D. Use of Anatomage tables in a large first year core unit. In: In: Proceedings of ASCILITE - Australian Society for Computers in Learning in Tertiary Education Annual Conference 2013; 2013. p. 298-302.

26. Fyfe S, Fyfe G, Dye D, et al. The anatomage table: differences in student ratings between initial implementation and established use. Focus Heal Prof Educ 2018; 19(2):41-52.

27. Paech D, Giesel FL, Unterhinninghofen R, et al. Cadaver-specific CT scans visualized at the dissection table combined with virtual dissection tables improve learning performance in general gross anatomy. Eur Radiol 2017; 27(5):2153-2160.

28. Yammine K, Violato C. A meta-analysis of the educational effectiveness of three-dimensional visualization technologies in teaching anatomy. Anat Sci Educ 2015; 8(6):525-538.

29. Peterson DC, Mlynarczyk GSA. Analysis of traditional versus threedimensional augmented curriculum on anatomical learning outcome measures. Anat Sci Educ 2016; 9(6):529-536

30. Guzman CR, Young S, Rabedeaux P, et al. Student perceived value of anatomy pedagogy, part II: clinical practice and assessment. J Med Educ Curric Dev 2015; 2. p. JMECD.S17497.

31. Pluta WJ, Richards BF, Mutnick A. PBL and beyond: trends in collaborative learning. Teach Learn Med 2013; 25(Suppl 1):S9-16.

\section{SUPPLEMENTARY MATERIALS}

Supplementary material associated with this article can be found in the online version at doi:10.1016/j.acra.2019.09.031. 